DOI: $10.15593 / 2224-9877 / 2018.1 .04$

УДК 622.248.54

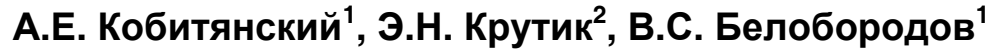 \\ ${ }^{1}$ Пермский национальный исследовательский политехнический университет, Пермь, Россия \\ ${ }^{2}$ ООО «Гидробур-сервис», Пермь, Россия

\section{ОПРЕДЕЛЕНИЕ ХАРАКТЕРИСТИК МЕХАНИЗМА ПОДАЧИ ДОЛОТА ВИНТОВОГО ЗАБОЙНОГО ДВИГАТЕЛЯ}

\begin{abstract}
Прихват колонны бурильных труб - один из самых распространенных видов аварий в практике бурения. Это явление возникает в случае превышения сил трения покоя над движущими силами инструмента. На долю такого типа аварий приходится более 60 \% осложнений в процессе бурения, причем в $40 \%$ случаев скважина ликвидируется или переоборудуется. Таким образом, явление прихвата колонны бурильных труб носит негативный характер и приводит к значительным материальным и моральным потерям. Вследствие этого проектирование и создание устройств по устранению прихватов бурильной колонны труб является важной и актуальной задачей.

Рассмотрены вопросы методики проектирования и расчета механизма подачи долота, конструкция которого представлена компанией ООО «Гидробур-сервис». Представлен принцип действия исследуемого механизма. Приведена его расчетная схема с учетом взаимосвязи с колонной бурильных труб, винтовым забойным двигателем и инструментом. Рассмотрены основные силовые и геометрические параметры, действующие на исследуемый механизм. В соответствии с предложенным алгоритмом разработан программный продукт MPDKOMP в системе Matlab R2014a, на основе которого получены значения основных характеристик механизма подачи долота и, в частности, осевого выдвигающего усилия, устраняющего эффект прихвата. Приведены табличные и графические иллюстрации одного из вариантов расчета для ряда исходных геометрических и силовых параметров системы компоновки низа бурильной колонны. С учетом полученных значений проведен прочностной расчет ряда основных конструктивных элементов всего механизма, подтверждающий его надежность и работоспособность.

Ключевые слова: прихват колонны бурильных труб, механизм подачи долота, винтовой забойный двигатель, осевое выдвигающее усилие, расчетная схема, участки профиля скважины, зенитный угол, программный продукт, прочностной расчет, математическая модель.
\end{abstract}

\author{
A.E. Kobityansky ${ }^{1}$, E.N. Krutik ${ }^{2}$, V.S. Beloborodov ${ }^{1}$ \\ ${ }^{1}$ Perm National Research Polytechnic University, Perm, Russian Federation \\ ${ }^{2}$ CJSC "Gidrobur-service", Perm, Russian Federation
}

\title{
DETERMINATION OF THE CHARACTERISTICS OF THE BIT FEEDING MECHANISM OF THE DOWNHOLE DRILLING MOTOR
}

Sticking of the drill string is one of the most common types of accidents in drilling practice. This phenomenon occurs in the case of excess frictional forces over the driving forces of the tool. This type of accident accounts for more than $60 \%$ of the complications in the drilling process, and in $40 \%$ of the cases the well is liquidated or re-equipped. Thus, the phenomenon of sticking a drill string is negative and leads to significant material and moral losses. As a result, the design and construction of devices to remove stuck pipe drillstring is an important and urgent problem.

In the article the questions of methodology of design and calculation of a feed mechanism of a bit, the design of which represented by CJSC "Gidrobur-service". The principle of operation of the mechanism under investigation is presented. Its design scheme is given taking into account the relationship with the drill string, the screw downhole motor and the tool. The main force and geometric parameters acting on the mechanism under investigation are considered. In accordance with the proposed algorithm, a software product MPDKOMP was developed in the Matlab R2014a system, on the basis of which the values of the main characteristics of the bit feed mechanism and in particular axial pulling force eliminating the sticking effect were obtained. Table and graphic illustrations of one of the calculation options for a number of initial geometric and power parameters of the bottom-hole assembly system are given. Taking into account the obtained values, a strength calculation of a number of basic structural elements of the entire mechanism has been carried out, confirming its reliability and efficiency.

Keywords: sticking of the drill string, bit feeding mechanism, downhole drilling motor, axial shear force, analytical model, borehole section, inclination angle, software product, strength calculation, mathematical model.

Механизм для ликвидации прихвата колонны бурильных труб (механизм подачи долота МПД) представляет собой телескопическую систему (рис. 1), основными узлами которой являются подвижный цилиндр 3 и неподвижный относительно него поршень 1 , связанный с колон- 
ной бурильных труб. МПД установлен над винтовым забойным двигателем (ВЗД) и соединен с ним с помощью резьбы. Основные детали и узлы механизма показаны на рис. 1.

В случае прихвата инструмента возникает осевое выдвигающее усилие, вызываемое ростом перепада давления бурового раствора, протекающего через ВЗД. Эта сила сдвигает подвижный цилиндр, двигатель и долото по направлению бурения без перемещения всей колонны. В результате разбуривания забоя долото с двигателем и цилиндром перемещается на ход МПД. Возврат цилиндра МПД в исходное положение осуществляется спуском колонны буровых труб.

Таким образом, значение осевого выдвигающего усилия механизма играет существенную роль для устранения эффекта прихвата колонны бурильных труб. Следует учесть, что на величину этой силы влияют профиль скважины и его участки, т.е. геометрические параметры забоя, ряд характеристик которых в соответствии с работами [1-5] представлен на рис. 2.

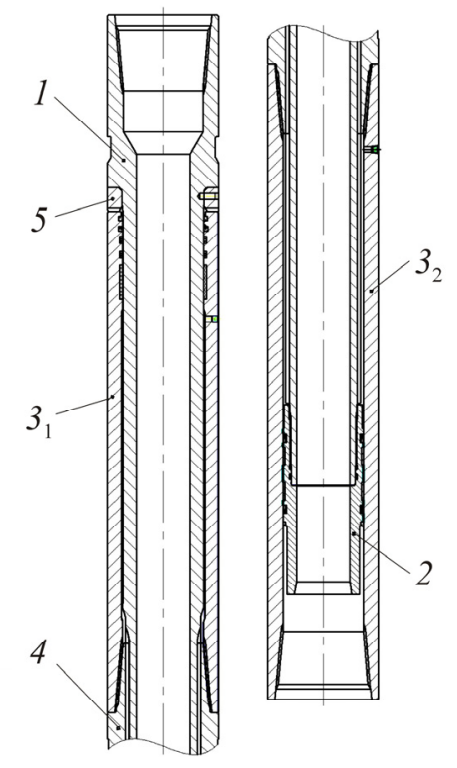

Рис. 1. Конструкция механизма подачи долота: 1 - поршень; 2 - шток; $3_{1}$ - цилиндр верх; $3_{2}$ - цилиндр низ; 4 - переводник; 5 - демпфер

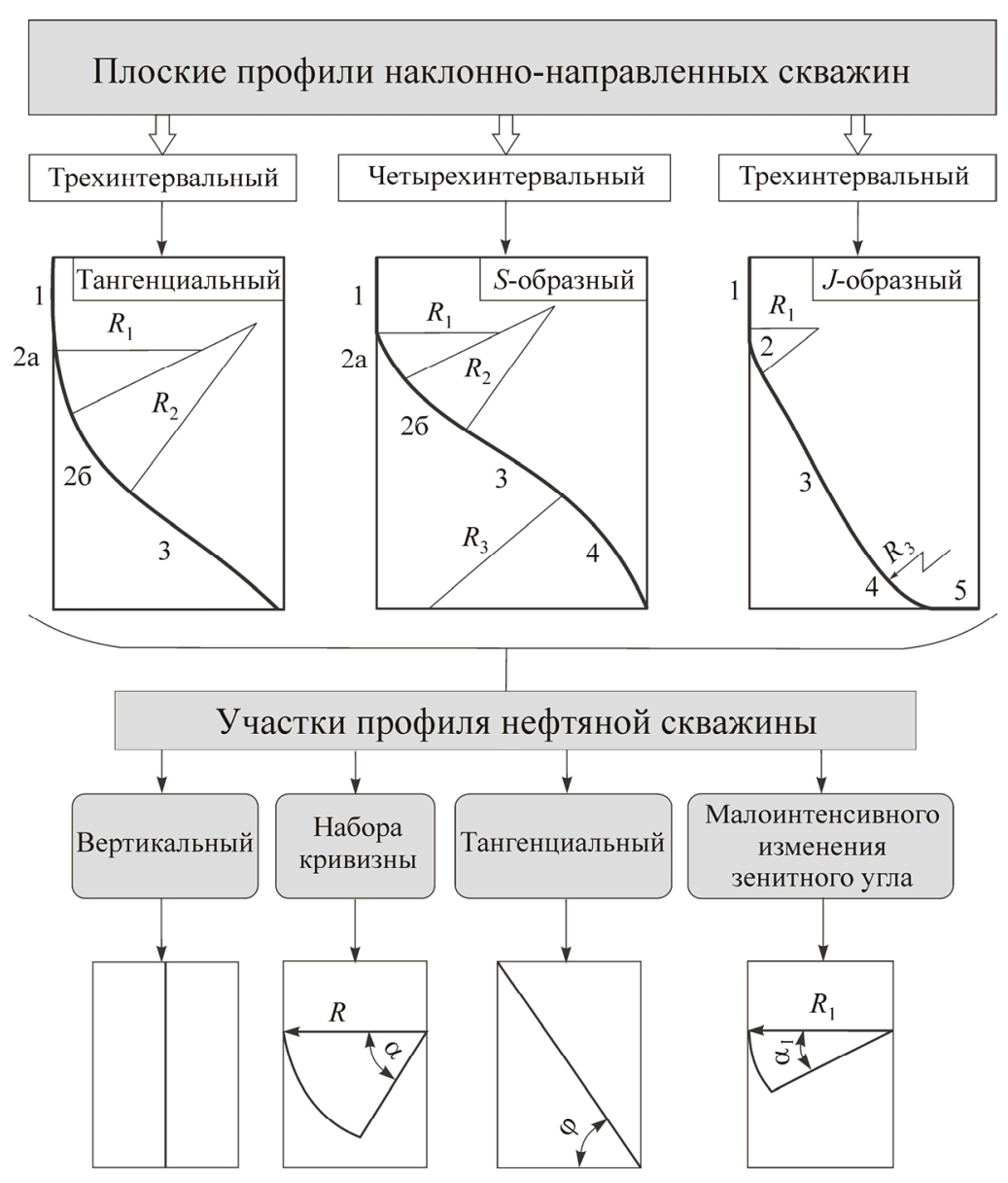

Рис. 2. Основные участки и профили буровой колонны 
В качестве примера рассматривается случай наклонного расположения участка скважины, расчетная схема которого приведена на рис. 3 .

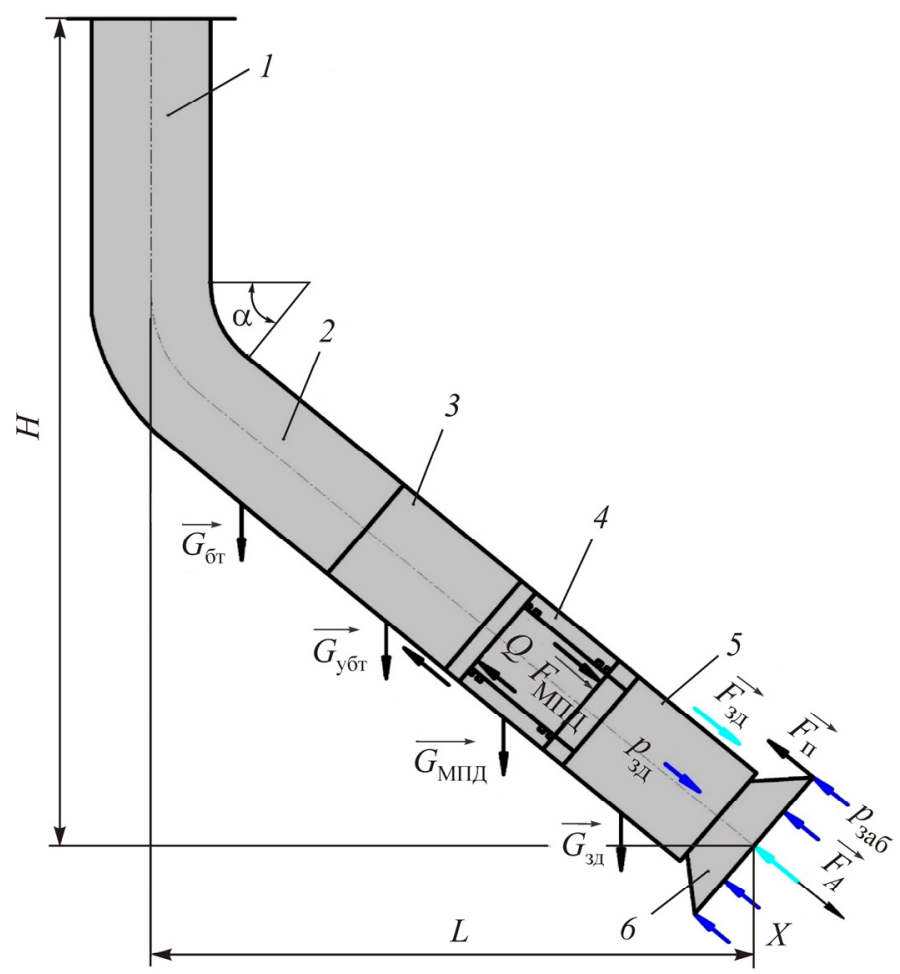

Рис. 3. Расчетная схема для случая наклонного расположения рассматриваемого участка: 1 - буровая колонна; 2 - бурильные трубы; 3 - утяжеленные бурильные трубы; 4 - механизм подачи долота;

5 - забойный двигатель; 6 - инструмент

При этом силовые характеристики, действующие на систему рис. 3, даны в табл. 1.

Таблица 1

Силы, действующие на рассматриваемый участок буровой колонны

\begin{tabular}{|c|c|c|}
\hline Обозначение & Название & Единицы измерения \\
\hline $\overrightarrow{G_{\text {зд }}}$ & Сила тяжести винтового забойного двигателя & $\mathrm{H}$ \\
\hline $\overrightarrow{G_{\mathrm{MПД}}}$ & Сила тяжести механизма подачи долота, равная $G_{ц и л}+G_{\Pi}$ & $\mathrm{H}$ \\
\hline $\overrightarrow{G_{\text {убт }}}$ & Сила тяжести участка утяжеленных бурильных труб & $\mathrm{H}$ \\
\hline $\overrightarrow{G_{\text {бт }}}$ & Сила тяжести легкосплавных бурильных труб & $\mathrm{H}$ \\
\hline $\overrightarrow{F_{\text {зд }}}$ & Осевое усилие на корпусе ВЗД & $\mathrm{H}$ \\
\hline $\overrightarrow{F_{\mathrm{A}}}$ & Выталкивающая (архимедова) сила & $\mathrm{H}$ \\
\hline $\overrightarrow{F_{\text {мпд }}}$ & Сила трения в цилиндре механизма подачи долота & $\mathrm{H}$ \\
\hline $\overrightarrow{F_{\Pi}}$ & Сила трения долота о горную породу & $\mathrm{H}$ \\
\hline $\overrightarrow{F_{\text {тр }}}$ & Сила трения от ВЗД, УБТ и цилиндра МПД о горную породу & $\mathrm{H}$ \\
\hline$\vec{Q}$ & Раскрывающее усилие МПД & $\mathrm{H}$ \\
\hline$p_{\text {зд }}$ & Перепад давления в винтовом забойном двигателе & МПа \\
\hline$p_{\text {заб }}$ & Забойное давление в нижнем сечении скважины & МПа \\
\hline
\end{tabular}


В качестве геометрических приняты следующие параметры:

- $L$ - длина горизонтального участка буровой колонны;

- $H$ - глубина колонны бурильных труб;

- зенитный угол $\alpha \in\left[0^{\circ} ; 90^{\circ}\right]$. Нижняя и верхняя границы значений угла $\alpha$ соответствуют вертикальному и горизонтальному расположению участка.

Основные соотношения для измерения геометрических и силовых параметров определяются в соответствии с размерами колонны бурильных труб, наличием определенного количества легкосплавных и утяжеленных труб $\sigma^{1}[1,6]$ при заданном перепаде давления в винтовом забойном двигателе.

Особо следует отметить силу $F$ реакции породы, приходящуюся на один зуб долота:

$$
\begin{gathered}
F=\frac{2 \mathrm{M}}{n D_{\text {д }}} ; \\
\mathrm{M}=\frac{n F D_{\text {д }}}{2},
\end{gathered}
$$

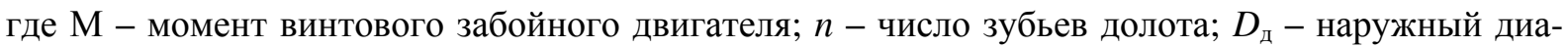
метр долота.

Благодаря этому определяется $F_{\text {п }}-$ сила трения от реакции породы (рис. 4):

$$
F_{\text {п }}=F_{n f},
$$

где $f_{2}$ - коэффициент трения пары металл-горная порода [1].

Сила трения за счет конструктивных особенностей МПД (уплотнения V-образного и круглого профиля, пара поршеньцилиндр и др.) определяется в соответствии с работой [7].

С учетом выбранных расчетной схемы и действующих в системе усилий определяется осевое выдвигающее усилие $\vec{Q}$ механизма подачи долота (см. рис. 3). Для удобства расчетов ось

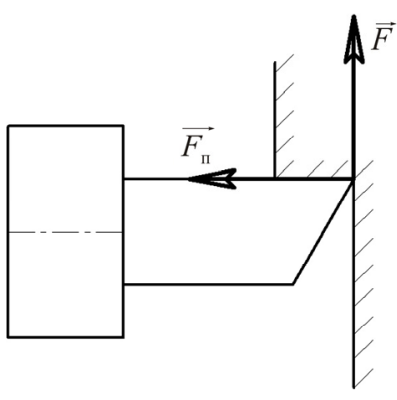

Рис. 4. Определение сопротивления $F_{\text {п }}$ абсцисс соответствует направлению силы $\vec{Q}$, а начало системы координат совпадает с началом первой легкосплавной трубы.

В результате условие равновесия системы сил на рассматриваемом участке приобретает следующий вид:

$$
\vec{Q}+\overrightarrow{F_{\text {зд }}}-\overrightarrow{F_{\mathrm{A}}}-\overrightarrow{F_{\text {п }}}-\overrightarrow{F_{\text {Мпд }}}+\sum_{i=1}^{4} \overrightarrow{G_{i}}-\sum_{j=1}^{2} \overrightarrow{F_{\text {тр } j}}=0,
$$

где $G_{i}$ - веса труб, а также веса элементов МПД, ВЗД и инструмента; $F_{\text {трj }}-$ силы трения от цилиндра МПД, ВЗД и долота.

Из формулы (1) следует, что значение раскрывающего усилия принимает вид

$$
\begin{gathered}
Q=-\left(G_{\text {МПд }}+G_{\text {бт }}+G_{\text {уббт }}+G_{\text {зд }}\right) k_{\mathrm{A}} \cos \alpha+ \\
+f_{2}\left(G_{\text {цил }}+G_{\text {зд }}\right) k_{\mathrm{A}} \sin \alpha-F_{\text {зд }}+F_{\mathrm{A}}+F_{\text {п }}+F_{\text {упл }}+T,
\end{gathered}
$$

где $k_{\mathrm{A}}$ - коэффициент облегчения в буровом растворе [1].

Полный расчет силового воздействия на долото при различных конструктивногеометрических характеристиках буровой колонны и получение осевого выдвигающего усилия осуществляются с помощью разработанного программного продукта MPDKOMP на основе Matlab R2014a [8] по следующему алгоритму (рис. 5):

\footnotetext{
${ }^{1}$ Гидробур-сервис [Электронный ресурс]. URL: http://gidrobur-s.ru (дата обращения: 04.01.2018).
} 


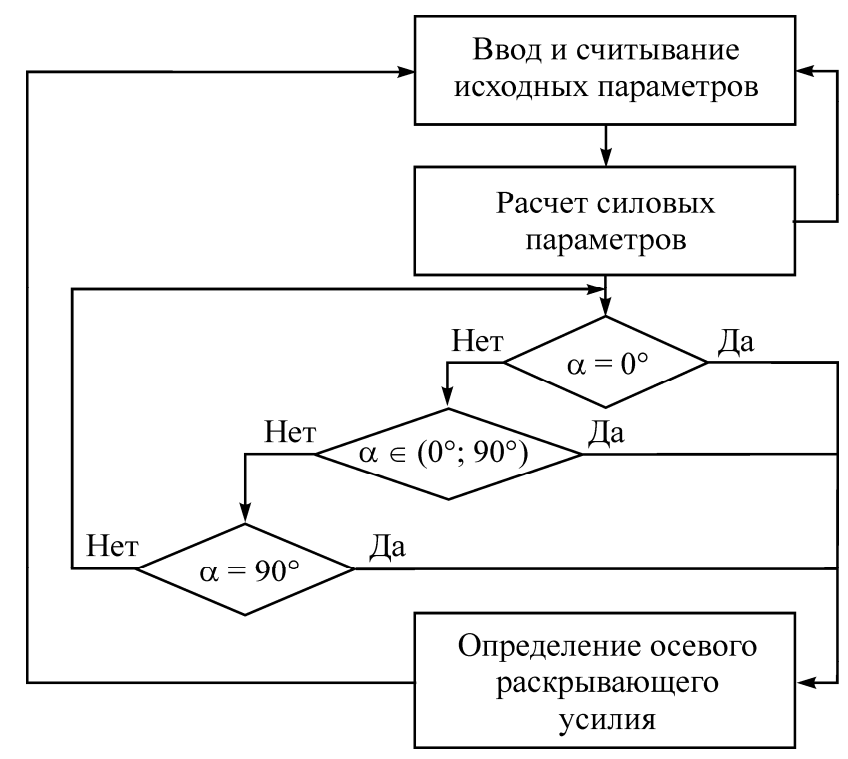

Рис. 5. Алгоритм расчета осевого выдвигающего усилия

Фрагмент результатов расчета усилия на долото $Q$, кН, в зависимости от момента винтового забойного двигателя М и зенитного угла $\alpha$ представлен в табл. 2.

Таблица 2

Фрагмент результатов расчета осевого выдвигающего усилия в зависимости от угла искривления и момента двигателя

\begin{tabular}{|c|c|c|c|c|c|c|c|c|c|c|}
\hline M, кН·м градус & 0 & 10 & 20 & 30 & 40 & 50 & 60 & 70 & 80 & 90 \\
\hline 2,6 & 6,9 & 7,2 & 7,8 & 8,7 & 9,8 & 11,1 & 12,6 & 14,2 & 15,9 & 17,6 \\
\hline 3,0 & 9,0 & 9,3 & 9,9 & 10,8 & 11,9 & 13,2 & 14,7 & 16,3 & 18,0 & 19,7 \\
\hline 3,4 & 11,1 & 11,4 & 12,0 & 12,9 & 13,9 & 15,3 & 16,8 & 18,4 & 20,1 & 21,8 \\
\hline 3,8 & 13,3 & 13,5 & 14,1 & 14,9 & 16,0 & 17,4 & 18,9 & 20,5 & 22,2 & 23,9 \\
\hline 4,2 & 15,4 & 15,6 & 16,2 & 17,0 & 18,2 & 19,5 & 20,9 & 22,6 & 24,3 & 26,0 \\
\hline 4,6 & 17,5 & 17,7 & 18,3 & 19,2 & 20,3 & 21,6 & 23,1 & 24,7 & 26,4 & 28,1 \\
\hline 5,0 & 19,6 & 19,8 & 20,4 & 21,3 & 22,4 & 23,7 & 25,2 & 26,8 & 28,5 & 30,2 \\
\hline 5,4 & 21,7 & 21,9 & 22,5 & 23,4 & 24,5 & 25,9 & 27,3 & 28,9 & 30,6 & 32,3 \\
\hline 5,8 & 23,8 & 24,0 & 24,6 & 25,5 & 26,6 & 27,9 & 29,4 & 31,0 & 32,7 & 34,4 \\
\hline 6,2 & 25,9 & 26,1 & 26,7 & 27,6 & 28,7 & 29,9 & 31,5 & 33,1 & 34,8 & 36,5 \\
\hline
\end{tabular}

Графическая иллюстрация проведенных расчетов представлена поверхностью на рис. 6.

Данный график может служить номограммой для выбора значений выталкивающей силы при определенных значениях момента винтового забойного двигателя М и зенитного угла $\alpha$.

Реализация полученных значений осевого выдвигающего усилия возможна при условии надежной и долговечной работы элементов всего механизма подачи долота. В связи с этим проведен прочностной расчет характеристик узлов и элементов МПД ${ }^{2}$ [9-13].

${ }^{2}$ ГОСТ 21425-75. Соединения зубчатые (шлицевые) прямобочные. Методы расчета нагрузочной способности. М.: Изд-во стандартов, 1975. 25 с. 

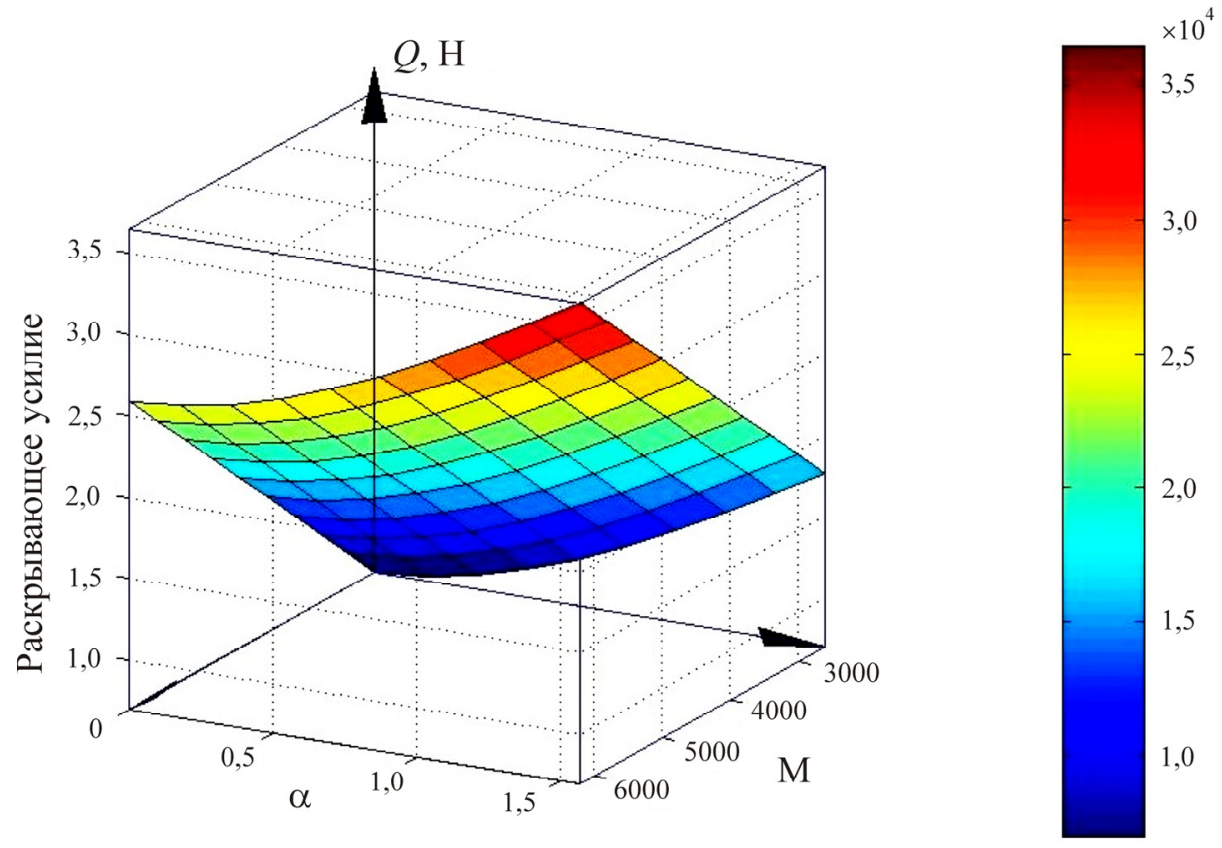

Рис. 6. Зависимость усилия $Q$

Основные этапы прочностных расчетов наиболее ответственных конструктивных элементов представлены на рис. 7.

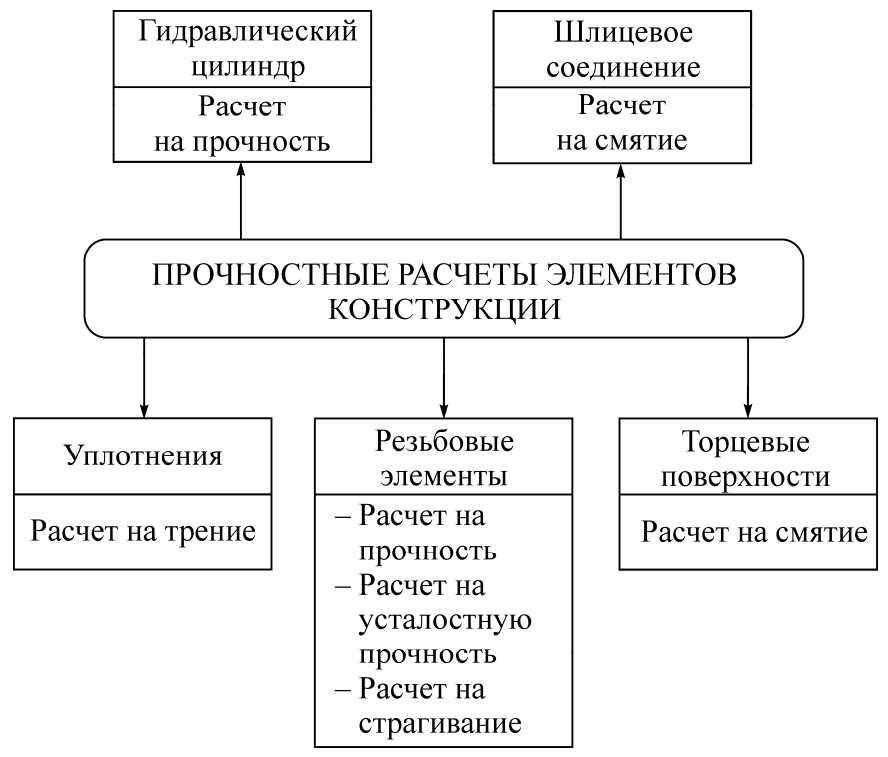

Рис. 7. Этапы и критерии расчетов деталей и узлов механизма подачи

Такие расчеты проводятся в автоматическом режиме для каждого полученного значения силы $Q$ в программе MPDKOMP [8].

В качестве примера в табл. 3 приведены результаты прочностных расчетов для случая максимального значения осевой силы при $\mathrm{M}=6,2 \mathrm{\kappa H} \cdot \mathrm{м}$ и $\Delta P=5$ МПа.

По результатам проведенных исследований можно сделать следующие выводы:

- предложена конструкция механизма подачи долота для устранения эффекта прихвата бурильной колонны труб;

- разработана расчетная схема и программное обеспечение для расчета параметров и характеристик механизма подачи долота; 
Таблица 3

Значения расчетных и допускаемых напряжений, действующих в узлах механизма

\begin{tabular}{|c|c|c|c|c|}
\hline Тип расчета & $\begin{array}{c}\text { Элемент } \\
\text { конструкции }\end{array}$ & $\begin{array}{c}\text { Расчетное } \\
\text { значение }\end{array}$ & $\begin{array}{l}\text { Допускаемое } \\
\text { значение }\end{array}$ & $\begin{array}{c}\text { Коэффициент } \\
\text { запаса } \\
\end{array}$ \\
\hline \multirow{2}{*}{ На прочность } & Резьба переводника & $306,55 \mathrm{MПа}$ & 413,3 МПа & 1,348 \\
\hline & Резьба поршня & 559,02 МПа & 620,0 МПа & 1,109 \\
\hline \multirow{2}{*}{ На страгивание } & Резьба переводника & $\begin{array}{l}\text { 1) } 631,72 \kappa \mathrm{KH} \\
\text { 2) } 885,97 \mathrm{\kappa H} \\
\end{array}$ & $\begin{array}{l}\text { 1) } 1073,9 \kappa \mathrm{H} \\
\text { 2) } 1506,57 \mathrm{\kappa H} \\
\end{array}$ & 1,7 \\
\hline & Резьба поршня & $\begin{array}{l}\text { 1) } 94,3 \mathrm{\kappa H} \\
\text { 2) } 83,0 \mathrm{\kappa H}\end{array}$ & $\begin{array}{l}\text { 1) } 160,3 \mathrm{\kappa H} \\
\text { 2) } 48,83 \mathrm{\kappa H}\end{array}$ & 1,7 \\
\hline \multirow{2}{*}{ На усталостную прочность } & Резьба переводника & - & - & 18,2 \\
\hline & Резьба поршня & - & - & 33,1 \\
\hline На смятие & Шлицевое соединение & 11,19 МПа & 15,0 МПа & 1,34 \\
\hline \multirow{2}{*}{$\begin{array}{l}\text { Ударных поверхностей } \\
\text { на смятие }\end{array}$} & Торец переводника & 111,23 МПа & \multirow[t]{2}{*}{ 1395,0 МПа } & 12,54 \\
\hline & Торец поршня & $111,23 \mathrm{MПа}$ & & 12,54 \\
\hline На прочность & Гидроцилиндр & $3,2 \mathrm{MM}$ & $20,0 \mathrm{MM}$ & 6,25 \\
\hline
\end{tabular}

- определены значения осевого выдвигающего усилия, необходимого для функционирования предложенной конструкции;

- прочностные расчеты основных элементов конструкции показали возможность ее эффективной и надежной работы.

\section{Список литературы}

1. Балденко Ф.Д. Расчеты бурового оборудования / Рос. гос. ун-т нефти и газа им. И.М. Губкина. - М., 2012. -428 c.

2. Расчет проектного профиля направленных и горизонтальных скважин: метод. указания / сост.: В.Ю. Близнюков, А.С. Повалихин, С.А. Кейн; Ухт. гос. техн. ун-т. - Ухта, 2014. - 40 с.

3. Бурение нефтяных и газовых скважин: метод. указ. и контр. задания для студ. заоч. отд-ния / сост. Д.В. Карасев. - Пермь: Изд-во Перм. нац. исслед. политехн. ун-та, 2012. - 43 с.

4. Расчет забойного устройства подачи долота многофункционального назначения: метод. указания / сост. Г.В. Буслаев; Ухт. гос. техн. ун-т. - Ухта, 2010. - 14 с.

5. Буслаев Г.В. Разработка забойного устройства подачи долота многофункционального назначения для бурения глубоких и направленных скважин: дис. ... канд. техн. наук. - Ухта, 2010. - 185 с.

6. Технология бурения нефтяных и газовых скважин: учеб. для студ. вузов: в 5 т. / под общ. ред. В.П. Овчинникова; Тюмен. гос. нефтегаз. ун-т. - Тюмень, 2014. - Т. 1. - 568 с.

7. Корпачев В.П., Андрияс А.А., Пережилин А.И. Основы проектирования объемного гидропривода: учеб. пособие / Сибир. гос. технолог. ун-т. - 3-е изд., перераб. и доп. - Красноярск, 2012. - 164 с.

8. Дьяконов В.П. МАTLAВ. Полный самоучитель. - М.: ДМК Пресс, 2012. - 768 с.

9. Куклин Н.Г., Куклина Г.С. Детали машин: учеб. - 4-е изд., перераб. и доп. - М.: Высш. шк., 1987. -383 c.

10. Куклин Н.Г., Куклина Г.С. Детали машин: учеб. - М.: Высш. шк., 1973. - 384 с.

11. Гордин П.В., Росляков Е.М., Эвелеков В.И. Детали машин и основы конструирования: учеб. пособие / Сев.-зап. открыт. техн. ун-т. - СПб., 2006. - 186 с.

12. Определение коэффициентов трения в резьбе и на торце гайки: метод. указания к лаб. раб. № 1 / сост.: Г.Н. Гаращук, А.А. Никифоров. - Томск: Изд-во Том. гос. архит.-строит. ун-та, 2007. - 18 с.

13. Расчет передач винт-гайка: метод. указания / сост.: Ю.И. Молодова, М.В. Жавнер, Д.В. Шляховецкий; СПб. гос. ун-т низкотемператур. и пищ. технологий. - СПб., 2006. - 40 с.

\section{References}

1. Baldenko F.D. Raschety burovogo oborudovaniia [Calculations of drilling equipment]. Rossiiskii gosudastvennyi universitet nefti i gaza imeni I.M. Gubkina, Moscow, 2012, 428 p. 
2. Blizniukov V.Iu., Povalikhin A.S., Kein S.A. Raschet proektnogo profilia napravlennykh i gorizontal'nykh skvazhin [Calculation of a design profile of the directed and horizontal wells]. Metodicheskie ukazaniia. Ukhtinskii gosudarstvennyi tekhnicheskii universitet, 2014, $40 \mathrm{p}$.

3. Karasev D.V. Burenie neftianykh i gazovykh skvazhin [Drilling of oil and gas wells]. Metodicheskie ukazaniia i kontrol'nye zadaniia dlia studentov zaochnogo otdeleniia. Perm': Izdatel'stvo Permskogo natsional'nogo issledovatel'skogo politekhnicheskogo universiteta, 2012, $43 \mathrm{p}$.

4. Buslaev G.V. Raschet zaboinogo ustroistva podachi dolota mnogofunktsional'nogo naznacheniia [Calculation of the bottomhole device of giving of a chisel of multipurpose appointment]. Metodicheskie ukazaniia. Ukhtinskii gosudarstvennyi tekhnicheskii universitet, 2010, 14 p.

5. Buslaev G.V. Razrabotka zaboinogo ustroistva podachi dolota mnogofunktsional'nogo naznacheniia dlia bureniia glubokikh i napravlennykh skvazhin [Development of the bottomhole device of giving of a chisel of multipurpose appointment for drilling of the deep and directed wells]. Ph. D. thesis. Ukhta, 2010, $185 \mathrm{p}$.

6. Tekhnologiia bureniia neftianykh i gazovykh skvazhin [Technology of drilling of oil and gas wells]. Ed. V.P. Ovchinnikova. Tiumenskii gosudarstvennyi neftegazovyi universitet, 2014, vol. 1, 568 p.

7. Korpachev V.P., Andriias A.A., Perezhilin A.I. Osnovy proektirovaniia ob"emnogo gidroprivoda [Bases of design of a volume hydraulic actuator]. Sibirskii gosudarstvennyi tekhnologicheskii universitet. 3nd ed. Krasnoiarsk, 2012, 164 p.

8. D'iakonov V.P. MATLAB. Polnyi samouchitel' [Full self-instruction manual]. Moscow: DMK Press, 2012, 768 p.

9. Kuklin N.G., Kuklina G.S. Detali mashin [Machine components]. 4nd ed. Moscow: Vysshaia shkola, $1987,383 \mathrm{p}$.

10. Kuklin N.G., Kuklina G.S. Detali mashin [Machine components] Moscow: Vysshaia shkola, 1973, 384 p.

11. Gordin P.V., Rosliakov E.M., Evelekov V.I. Detali mashin i osnovy konstruirovaniia [Details of cars and basis of designing]. Severo-zapadnyi otkrytyi tekhnicheskii universitet. Saint-Petersburg, 2006, 186 p.

12. Garashchuk G.N., Nikiforov A.A. Opredelenie koeffitsientov treniia v rez'be i na tortse gaiki [Determination of coefficients of friction in a carving and at a nut end face]. Izdatel'stvo Tomskogo gosudarstvennogo arkhitekturnogo-stroitel'nogo universiteta, 2007, 18 p.

13. Molodova Iu.I., Zhavner M.V., Shliakhovetskii D.V. Raschet peredach vint-gaika [Calculation of transfers screw nut]. Sankt-Peterburgskii Gosudarstvennyi universitet nizkotemperaturnykh i pishchevykh tekhnologii, 2006, 40 p.

Получено 24.01.2018

\section{Об авторах}

Кобитянский Алексей Ефимович (Пермь, Россия) - кандидат технических наук, доцент, профессор кафедры материалов, технологий и конструирования машин Пермского национального исследовательского политехнического университета; e-mail: allania00@ mail.ru.

Крутик Эрнст Николаевич (Пермь, Россия) - кандидат технических наук, заместитель генерального директора по новой технике компании ООО «Гидробур-сервис»; e-mail: EKrutik@gbs.nt-serv.com.

Белобородов Владимир Сергеевич (Пермь, Россия) - аспирант кафедры инновационных технологий машиностроения Пермского национального исследовательского политехнического университета; e-mail: beloborodovvova@mail.ru.

\section{About the authors}

Alexey E. Kobityansky (Perm, Russian Federation) - Ph. D. in Technical Sciences, Associate Professor, Professor, Department of Materials, Technologies and Constructions of Machines, Perm National Research Polytechnic University; e-mail: allania00@mail.ru.

Ernst N. Krutik (Perm, Russian Federation) - Ph. D. in Technical Sciences, Deputy General Director for New Technology, Company CJSC “Gidrobur-service”; e-mail: EKrutik@gbs.nt-serv.com.

Vladimir S. Beloborodov (Perm, Russian Federation) - Postgraduate Student, Department of Innovative Engineering Technologies, Perm National Research Polytechnic University; e-mail: beloborodovvova@mail.ru. 